\title{
APACHE busca soluciones de embalaje activas e inteligentes para la conservación preventiva
}

El 1 de enero de 2019 comenzaba su andadura APACHE (Active \& intelligent Packaging materials and display cases as a tool for preventive conservation of Cultural Heritage) ${ }^{1}$; de carácter internacional y financiado por la UE, es un proyecto en proceso cuyo objetivos explicita el desglose de sus siglas: el desarrollo de materiales de embalaje activos e inteligentes como herramientas para la conservación preventiva del patrimonio cultural. Hasta 26 socios de 12 países diferentes están implicados en un trabajo que se extiende hasta el año 2022.

Antonio Mirabile | proyecto APACHE

Url de la contribución <www.iaph.es/revistaph/index.php/revistaph/article/view/4533>

La degradación del patrimonio cultural mueble puede incrementarse considerablemente debido a unas condiciones ambientales adversas e inestables, la luz y la contaminación (intrínseca o externa) ${ }^{2}$. La conservación preventiva tiene como objetivo minimizar el envejecimiento y la degradación, optimizando las soluciones para la exhibición y el almacenamiento. Cabe destacar que sólo se expone un porcentaje muy reducido de todas las piezas de museos; a menudo, la gran mayoría se encuentra almacenada en condiciones ambientales inadecuadas, especialmente en museos de tamaño mediano y pequeño. En los últimos años, se han desarrollado y empezado a utilizar diversos materiales de embalaje activos e inteligentes, especialmente en ramas de la industria alimentaria. Sin embargo, estos materiales representan soluciones a corto plazo y no pueden adaptarse fácilmente al ámbito del patrimonio cultural, donde la estabilidad a largo plazo es indispensable.

Dentro de la propuesta APACHE, la innovadora combinación de nuevos materiales activos de embalaje proporciona sistemas inteligentes, de bajo coste y fáciles de implementar de cara al almacenamiento y la exposición de piezas. Estos soportes materiales son desarrollados a partir del modelado de materiales, con sensores y tecnología de sensores inalámbricos. Uno de los principales objetivos de APACHE es reducir drásticamente los costes de los sistemas mecánicos de control y monitorización de climatización mediante el desarrollo y la personalización de novedosos materiales inteligentes y asequibles que se basan en los avances de la ciencia de los materiales y en la modelización discreta y continua. Estos innovadores materiales activos sustituyen a los dispositivos pasivos de muestreo y a los sistemas de monitorización actualmente utilizados, los cuales son caros, engorrosos de calibrar y no detectan una medición correcta a tiempo. Además, estos mismos sistemas sufren fallos de durabilidad y confiabilidad, a menudo más que las muestras que deben ayudar a proteger.

El objetivo del proyecto APACHE es el desarrollo de herramientas/soluciones para una conservación preventiva eficaz y asequible. La investigación se centrará en dos aspectos:

$>$ Soluciones de embalaje y vitrinas/cajas activas, utilizando materiales funcionales innovadores que influyen e interactúan activamente con los objetos embalados. Permiten la liberación/adsorción de sustancias del objeto embalado o de su atmósfera circundante dentro de su recinto cerrado. Para minimizar los procesos de degradación de los objetos de patrimonio cultural, se utilizarán componentes activos para crear un ambiente estable y optimizado dentro de los recintos cerrados mediante la compensación de las fluctuaciones de temperatura y humedad, la adsorción o los contaminantes transportados por el aire y que proporcionan una protección antifúngica. Para ello, es necesario optimizar y diseñar materiales específicos, aprovechando las ventajas de la modelización de materiales. 


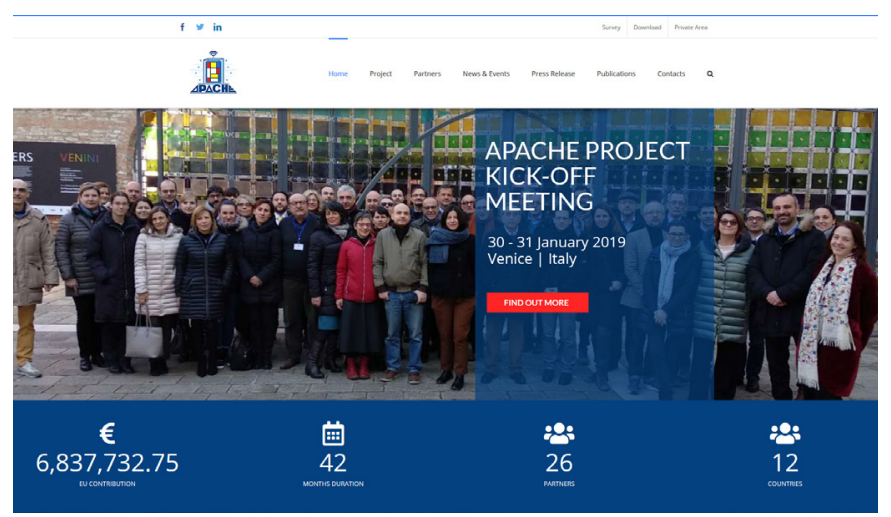

Web del proyecto

> Herramientas inteligentes de embalaje y vitrinas/cajas, es decir, herramientas que dotan al embalaje de una función adicional. Éstas incluyen sensores que monitorean el estado del objeto embalado o del ambiente que lo rodea y que se comunican a través de la tecnología de sensores inalámbricos, tales como las redes inalámbricas de sensores y los dispositivos de identificación por radiofrecuencia. Los sensores se colocarán dentro de las cajas de almacenamiento y vitrinas, y actuarán como dispositivos "inteligentes" para proporcionar las condiciones ideales para proteger las obras de arte tanto durante el almacenamiento como durante la exposición.

Se tomarán en consideración cuatro clases de materiales de arte, ya que estos se encuentran frecuentemente en "colecciones mixtas" (polimateriales y compuestos) y se caracterizan por sus emisiones gaseosas como resultado del envejecimiento natural:

> obras de arte/objetos orgánicos (cuero, madera, pergamino, textiles);

> obras de arte de plástico y otros objetos artísticos sintéticos;

$>$ pinturas y colorantes modernos (es decir, producidos industrialmente);

> papel de fabricación industrial y objetos compuestos de madera (archivos, dibujos, maquetas, fotografías).
El proyecto tendrá un desarrollo progresivo. Comienza con una modelización de materiales a escala múltiple para predecir la degradación de los materiales relacionados con los objetos de arte y para determinar la tasa de emisión de compuestos orgánicos volátiles de los materiales de embalaje y de la propia obra de arte. Estos datos se utilizarán como referencia para el desarrollo de sensores. Un segundo paso importante será el diseño de nuevas herramientas y soluciones para la monitorización y el control/ajuste de las condiciones ambientales cerradas (en cajas y vitrinas). Los socios de APACHE crearán reguladores optimizados de temperatura y humedad relativa, novedosos absorbentes para contaminantes y membranas antifúngicas. El segundo paso se verá reforzado con la fabricación de innovadores sensores dirigidos a la detección de compuestos orgánicos volátiles, contaminantes, humedad relativa y temperatura. Los sensores desarrollados se integrarán posteriormente de forma electrónica en una plataforma inalámbrica de sensores y redes. A la primera fase de investigación e innovación le seguirá una fase que se dedica a los usuarios finales y a los posibles interesados, con el desarrollo de una herramienta de software. Así, los responsables de la toma de decisiones pueden visualizar qué efecto tiene una u otra decisión sobre la longevidad del objeto almacenado. En esta fase se organizará también una serie de cursos de formación y talleres sobre la utilización de los nuevos materiales, que estarán abiertos tanto a sectores industriales como a museos, empresas de restauración, investigadores, la administración e institutos tecnológicos.

El proyecto APACHE ha recibido una contribución de la UE de un importe de 6.837.732,75€.

\section{NOTAS}

1. Más información en http://www.apacheproject.eu/

2. Este texto ha sido traducido por Victoria Frensel. 